\title{
ChemComm
}

\section{A new Keggin-like niobium-phosphate cluster that reacts reversibly with hydrogen peroxide $\dagger$}

Cite this: Chem. Commun., 2015, 51,12744

Received 6th May 2015,

Accepted 24th June 2015

DOI: $10.1039 /$ c5cc03782d

www.rsc.org/chemcomm

Polyoxoniobate clusters that are stable in acidic solutions are rare and particularly useful in industrial processes. Here we report a new pentaphosphate niobate polyoxometalate cluster (TMA) ${ }_{9} \mathrm{H}_{3} \mathrm{Nb}_{9} \mathrm{P}_{5} \mathrm{O}_{41} \cdot 28 \mathrm{H}_{2} \mathrm{O}$ $\left(\mathrm{Nb}_{9} \mathrm{P}_{5}\right)$ that is stable over a wide $\mathrm{pH}$ range and that can be converted reversibly into the peroxo form.

The layered niobium-phosphate hydrate $\left(\mathrm{NbOPO}_{4} \cdot x \mathrm{H}_{2} \mathrm{O}\right)$ is a useful catalyst for biomass conversion, such as the conversion of sugars to 5-hydroxymethylfurfural (HMF) and other dehydration reactions. ${ }^{1}$ Its structure consists of corner-shared $\mathrm{NbO}_{6}$ and $\mathrm{PO}_{4}$ units ${ }^{2}$ and the coexistence of both basic and acidic sites in $\mathrm{NbOPO}_{4} \cdot x \mathrm{H}_{2} \mathrm{O}$ is responsible for its catalytic activity. ${ }^{3}$ Although niobium phosphate is widely used as a catalyst, its solution chemistry is rarely studied. Among the previous Keggin-type polyoxoniobates, ${ }^{4}$ Nyman et al. reported phosphate-decorated lacunary Keggin-type polyoxoniobate as an insoluble sodium salt, $\mathrm{Na}_{15}\left[\left(\mathrm{PO}_{2}\right)_{3} \mathrm{PNb}_{9} \mathrm{O}_{34}\right] \cdot 22 \mathrm{H}_{2} \mathrm{O}\left(\mathrm{Nb}_{9} \mathrm{P}_{4}\right)$, which was characterized by crystallography and MAS NMR. ${ }^{5}$ Recently we synthesized sets of peroxoniobophosphate clusters as water-soluble precursors for electron-beam-patterned niobium-phosphate films. ${ }^{6}$ Among them, the $\left[\mathrm{HNb}_{4} \mathrm{P}_{2} \mathrm{O}_{14}\left(\mathrm{O}_{2}\right)_{4}\right]^{5-}$ cluster (peroxo- $\mathrm{Nb}_{4} \mathrm{P}_{2}$ ) is stable over a wide $\mathrm{pH}$ range, spanning into acidic conditions, which is remarkable in itself because polyoxoniobates are generally only stable and soluble in neutral to basic solutions. We here report the synthesis, structure and characterization of a Keggin-like mixed niobium-phosphate cluster as a highly soluble tetramethylammonium (TMA) salt, (TMA) ${ }_{9} \mathrm{H}_{3} \mathrm{Nb}_{9} \mathrm{P}_{5} \mathrm{O}_{41} \cdot 28 \mathrm{H}_{2} \mathrm{O}\left(\mathrm{Nb}_{9} \mathrm{P}_{5}\right)$. The new cluster $\mathrm{Nb}_{9} \mathrm{P}_{5}$ features a central phosphate and four additional phosphates in the outer layers.

The $\mathrm{Nb}_{9} \mathrm{P}_{5}$ cluster was synthesized by hydrothermal reaction of hydrous niobium oxide, TMAOH and phosphoric acid.

\footnotetext{
${ }^{a}$ Department of Chemistry, University of California, Davis, One Shields Ave. Davis, CA 95616, USA. E-mail: junghoson@gmail.com

${ }^{b}$ Department of Chemistry, Department of Earth and Planetary Sciences,

University of California, Davis, One Shields Ave. Davis, CA 95616, USA

$\dagger$ Electronic supplementary information (ESI) available: Experimental details, crystallographic data, ESI-MS, FT-IR, Raman and TGA data. CCDC 1062824. See DOI: $10.1039 / \mathrm{c} 5 \mathrm{cc} 03782 \mathrm{~d}$
}
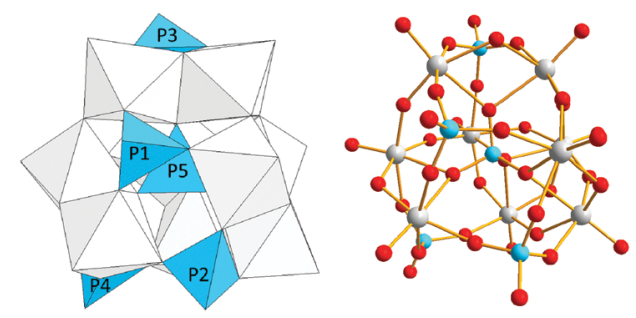

Fig. 1 Polyhedral (left) and ball-and-stick (right) drawing of $\mathrm{Nb}_{9} \mathrm{P}_{5}$ cluster (Nb: gray, P: blue, O: red).

The solution $\mathrm{pH}$ is a key factor for the formation of $\mathrm{Nb}_{9} \mathrm{P}_{5}$. In the given synthesis condition (see $\mathrm{ESI} \dagger$ ), $\mathrm{Nb}_{9} \mathrm{P}_{5}$ forms exclusively and the solution $\mathrm{pH}=9$ after reaction. When a larger amount of TMAOH was used to make $\mathrm{pH}=10$ after reaction, a mixture of $\mathrm{Nb}_{9} \mathrm{P}_{5}$ and Keggin-type $\left[\mathrm{PNb}_{14} \mathrm{O}_{42}\right]^{9-}$ cluster $\left(\mathrm{PNb}_{14}\right)$ formed, ${ }^{7}$ as we determined by electrospray-ionization mass spectrometry (ESI-MS). The $\mathrm{PNb}_{14}$ dominated when the $\mathrm{pH}$ of the reaction solution was higher than 11 .

The shape of $\mathrm{Nb}_{9} \mathrm{P}_{5}$ is similar to the Keggin-type cluster, but it possesses no symmetry [Fig. 1]. There are some irregularly shaped polyoxoniobate clusters reported previously. ${ }^{8}$ Symmetry is lost in $\mathrm{Nb}_{9} \mathrm{P}_{5}$ because of the multiple substitutions of $\mathrm{PO}_{4}$ groups for the different $\mathrm{NbO}_{6}$ sites in the normal Keggin structure. The structure of $\mathrm{Nb}_{9} \mathrm{P}_{5}$ is significantly different from $\mathrm{Nb}_{9} \mathrm{P}_{4}$, which possesses pseudo- $C_{3}$ symmetry. ${ }^{5}$ The previous $\mathrm{Nb}_{9} \mathrm{P}_{4}$ structure has three neighboring phosphate groups bound to the lacunary-Keggin $\mathrm{PNb}_{9}$ unit and there are two coordinating $\mathrm{Na}^{+}$ions between the phosphate groups. Examples of similar mixed-addenda polyoxometalates with group 15 elements include an arsenate-containing polyoxovanadate. ${ }^{9}$ In the structure of $\mathrm{Nb}_{9} \mathrm{P}_{5}$, there are four metal-oxo triads bonded to the central phosphate. The basal plane of the $\mathrm{Nb}_{9} \mathrm{P}_{5}$ cluster in Fig. 1 (farthest from the viewer) is a regular $\mathrm{Nb}_{3} \mathrm{O}_{13}$ triad, which is a common building unit in Keggin ions. The other three triads are $\mathrm{Nb}_{2} \mathrm{PO}_{12}$ moieties. The two $\mathrm{Nb}_{2} \mathrm{PO}_{12}$ triads are in a similar orientation, with $\mathrm{P} 3$ and $\mathrm{P} 4$ coordinating the basal $\mathrm{Nb}_{3} \mathrm{O}_{13}$ triad, while the other $\mathrm{Nb}_{2} \mathrm{PO}_{12}$ triad that contains $\mathrm{P} 2$ is rotated about $120^{\circ}$ counterclockwise relative to 
the others. These three $\mathrm{Nb}_{2} \mathrm{PO}_{12}$ triads are connected by an additional phosphate (P1) at the top of the $\mathrm{Nb}_{9} \mathrm{P}_{5}$ cluster (closest from viewer). In the crystal structure, nine TMA countercations are found and this number of TMA agrees with elemental analysis result. Thus three charge-balancing protons should be bound on the cluster to make the formula as $\left[\mathrm{H}_{3} \mathrm{Nb}_{9} \mathrm{P}_{5} \mathrm{O}_{41}\right]^{9-}$. The positions of the protons could not be determined, by either crystallography nor by bond-valence sum calculation of the oxygen atoms.

The ESI-MS of the $\mathrm{Nb}_{9} \mathrm{P}_{5}$ cluster [Fig. S1, ESI $\dagger$ ] exhibit a relatively complex multi-peak pattern when compared to simpler spectra of other substituted polyoxoniobate clusters that we have synthesized. ${ }^{6,7,10}$ There are multiple side peaks near the assigned peaks, which could be due to loss or addition of water from the $\mathrm{Nb}_{9} \mathrm{P}_{5}$ cluster during the ionization or drying steps in the ESI-MS analysis. Multiple side peaks in ESI-MS were also observed for $\left[\mathrm{H}_{2} \mathrm{Mn}^{\mathrm{IV}} \mathrm{Nb}_{10} \mathrm{O}_{32}\right]^{8-}$ cluster. $^{11}$ There are also some unassigned peaks between $800<m / z<950$, which must be due to fragmentation of $\mathrm{Nb}_{9} \mathrm{P}_{5}$.

The ${ }^{31} \mathrm{P}$ NMR spectrum of an aqueous $\mathrm{Nb}_{9} \mathrm{P}_{5}$ solution shows four phosphate peaks assignable to the cluster [Fig. 2]. The integrated peak areas, from left to right, are approximately $1: 2: 1: 1$, which agree with five different phosphate groups in the cluster stoichiometry. We hypothesized that the average $\mathrm{P}-\mathrm{O}$ lengths within $\mathrm{PO}_{4}$ groups [Fig. S2, ESI $\dagger$ ] and ${ }^{31} \mathrm{P}$ chemical shifts are related. Assuming that the chemical shift depends on the average $\mathrm{P}-\mathrm{O}$ lengths to the nucleus, we assign the peak at $-1.2 \mathrm{ppm}$ as the central phosphate (P5), the peak at $-3.8 \mathrm{ppm}$ as P1 and P4. These P1 and P4 have similar average $\mathrm{P}-\mathrm{O}$ lengths, so the merged peak in the NMR spectra is understandable if the chemical shieldings were also similar. Accordingly, we assign the peak at -6.4 as P2, and the most upfield peak at $-\mathbf{1 1 . 3} \mathrm{ppm}$ as $\mathrm{P}$. The peak assignment is also in agreement with the peak widths. The $\mathrm{P} 3$ has the widest range of $\mathrm{P}-\mathrm{O}$ lengths in the X-ray structure, and also the broadest peak in the NMR spectra, and the central P5 has the most regular $\mathrm{P}-\mathrm{O}$ lengths and correspondingly the sharpest peak. The correlation suggests that asymmetry of the ${ }^{31} \mathrm{P}$ nuclei are reflected in the spectra. The ${ }^{31} \mathrm{P}$ MAS NMR spectra shows three overlapping peaks $(-1.6$, -2.4 , and $-3.2 \mathrm{ppm}$ ) in the more downfield region and a broader upfield peak at $-10.1 \mathrm{ppm}$ [Fig. 2]. Deconvolution and integration of the peaks gives approximate ratios of $1: 2: 2$ for (-1.6 ppm and $-2.4 \mathrm{ppm}):-3.2 \mathrm{ppm}:-10.1 \mathrm{ppm}$ peaks. The peaks at -1.6 and $-2.4 \mathrm{ppm}$ are assigned to the central P5.

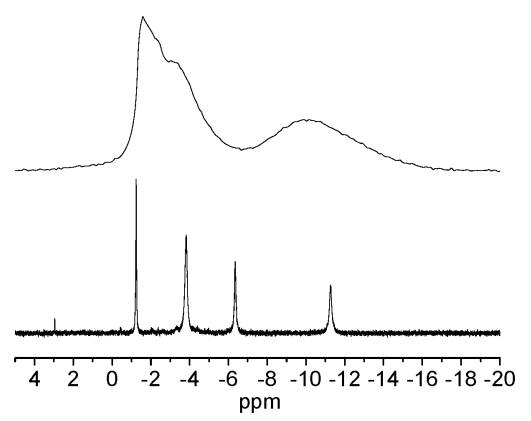

Fig. $2{ }^{31} \mathrm{P}$ MAS-NMR (top) and ${ }^{31} \mathrm{P}$ solution NMR (bottom, $30 \mathrm{mM}$ in $\mathrm{D}_{2} \mathrm{O}$ ) spectra of $\mathrm{Nb}_{9} \mathrm{P}_{5}$.
Similarly to the solution ${ }^{31} \mathrm{P}$ NMR peak assignment, the $-3.2 \mathrm{ppm}$ peak is assigned to $\mathrm{P} 1$ and $\mathrm{P} 4$, and the peak at $-10.1 \mathrm{ppm}$ is assigned to $\mathrm{P} 2$ and $\mathrm{P} 3$. In the ${ }^{31} \mathrm{P}$ MAS NMR study of $\mathrm{Nb}_{9} \mathrm{P}_{4}$, two broad peaks were observed at 6.1 and $1.4 \mathrm{ppm}$, and these are assigned to outer phosphate and central phosphate groups, respectively. ${ }^{5}$ We speculate that the considerable downfield shift of the outer phosphate group in $\mathrm{Nb}_{9} \mathrm{P}_{4}$ compared to $\mathrm{Nb}_{9} \mathrm{P}_{5}$ can be due to the coordination of $\mathrm{Na}^{+}$.

The $\mathrm{Nb}_{9} \mathrm{P}_{5}$ was also characterized via FT-IR and Raman spectroscopy [Fig. S3, ESI $\dagger$ ]. The FT-IR spectra show multiple P-O bands in the range of 1000-1200 cm $\mathrm{cm}^{-1}$, which arise from different $\mathrm{PO}_{4}$ groups. The $\mathrm{Nb}=\mathrm{O}$ band is located at $900 \mathrm{~cm}^{-1}$ and weaker $\mathrm{M}-\mathrm{O}-\mathrm{M}$ bands are observed below $800 \mathrm{~cm}^{-1}$. In the Raman spectra, multiple overlapping $\mathrm{Nb}=\mathrm{O}$ bands near $900 \mathrm{~cm}^{-1}$ are observed, possibly due to the asymmetric structure of $\mathrm{Nb}_{9} \mathrm{P}_{5}$. We assign the weak bands in $950-1100 \mathrm{~cm}^{-1}$ to different $\mathrm{PO}_{4}$ groups.

The stability of the $\mathrm{Nb}_{9} \mathrm{P}_{5}$ cluster in different $\mathrm{pH}$ conditions was examined by using ESI-MS [Fig. S4, ESI $\dagger$ ]. The pH of the $6 \mathrm{mM}$ solution of $\mathrm{Nb}_{9} \mathrm{P}_{5}$ was 7.3, and the cluster was apparently kinetically stable in solution for many months. The $\mathrm{Nb}_{9} \mathrm{P}_{5}$ cluster was stable until pH 12 when titrated with TMAOH. The cluster was also kinetically stable when titrated with $\mathrm{HCl}$ until $\mathrm{pH} 3$. The solution at $\mathrm{pH}<3$, however, became a transparent hydrogel after a few days, which indicates a slow proton-induced charge neutralization, rearrangement and condensation.

The key point is that this $\mathrm{Nb}_{9} \mathrm{P}_{5}$ cluster provides another example of an aqueous niobate cluster that can be processed in acidic solutions. This stability in acidic region was also observed for the peroxoniobophosphates, ${ }^{6}$ but most of other polyoxoniobate clusters tend to precipitate as hydrous niobium oxide below $\mathrm{pH} \leq 4-5$.

We found that the $\mathrm{Nb}_{9} \mathrm{P}_{5}$ cluster could be reversibly converted to the peroxo- $\mathrm{Nb}_{4} \mathrm{P}_{2}$ cluster [Scheme 1] when $\mathrm{H}_{2} \mathrm{O}_{2}$ is added. The conversion process was monitored via ESI-MS and ${ }^{31} \mathrm{P}$ NMR after addition of the stoichiometric amount of $\mathrm{H}_{2} \mathrm{O}_{2}$. In the ESI-MS, we observed a set of new complex peaks with lower intensity in the $m / z$ regions near those of the $\mathrm{Nb}_{9} \mathrm{P}_{5}$ [Fig. 3]. These new peaks persist for many hours after adding $\mathrm{H}_{2} \mathrm{O}_{2}$. This persistence suggests that peroxo- $\mathrm{Nb}_{9} \mathrm{P}_{5}$ or similar peroxo-Keggin-like species form. We failed to isolate these transient species for crystallization. Other new peaks centered at $\mathrm{m} / z=288.8$ grew and diminished in an hour after adding $\mathrm{H}_{2} \mathrm{O}_{2}$. We assign this putative new species as $\left[\mathrm{H}_{3} \mathrm{Nb}_{5} \mathrm{PO}_{13}\left(\mathrm{O}_{2}\right)_{5}\right]^{3-}$, based on $m / z$ value [Fig. 3]. The evolution of ESI-MS peaks show that the peroxo$\mathrm{Nb}_{4} \mathrm{P}_{2}$ forms exclusively with time. To further understand the

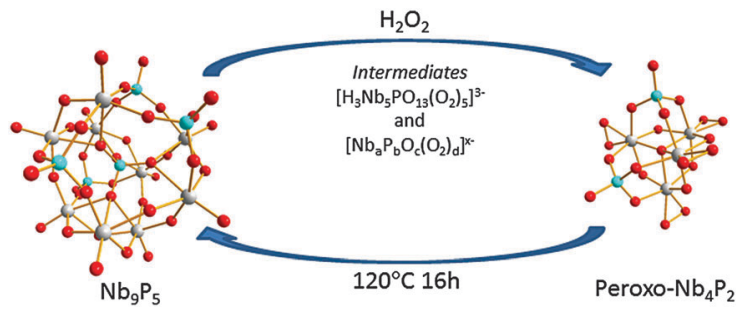

Scheme 1 The interconversion reaction between $\mathrm{Nb}_{9} \mathrm{P}_{5}$ and peroxo- $\mathrm{Nb}_{4} \mathrm{P}_{2}$ 


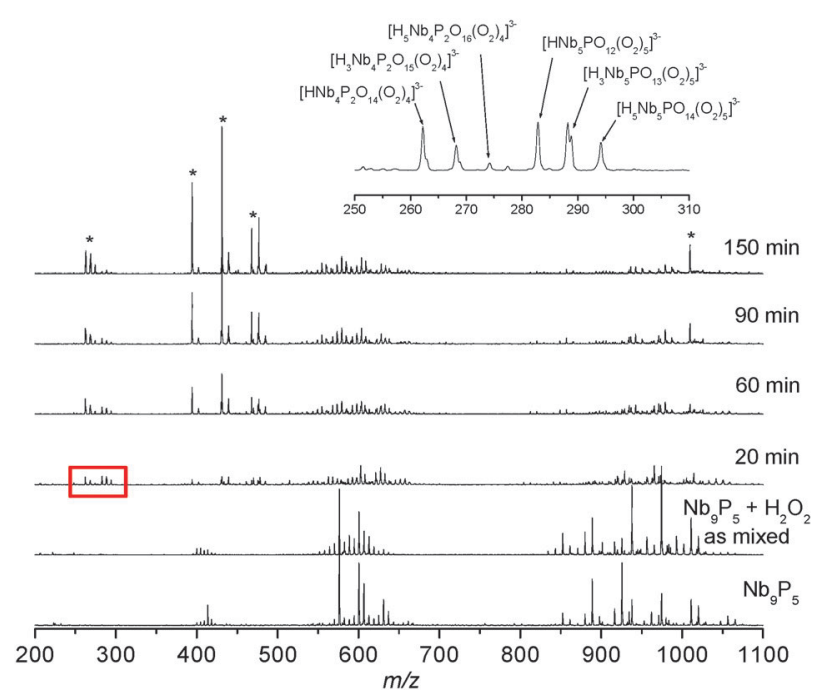

Fig. 3 Time-dependent ESI-MS spectra of $\mathrm{Nb}_{9} \mathrm{P}_{5}$ solution after adding 2 equivalents of $\mathrm{H}_{2} \mathrm{O}_{2}$. The inset shows more detailed peak assignments. The peaks marked with asterisks correspond to peroxo- $-\mathrm{Nb}_{4} \mathrm{P}_{2}$.

reaction, ${ }^{31} \mathrm{P}$ NMR spectra were collected after adding $\mathrm{H}_{2} \mathrm{O}_{2}$ [Fig. 4]. The ${ }^{31} \mathrm{P}$ NMR peaks of $\mathrm{Nb}_{9} \mathrm{P}_{5}$ shift and split after addition of hydrogen peroxide, which indicates that a range of different peroxo- $\mathrm{Nb}_{9} \mathrm{P}_{5}$ or similar compounds form as transient intermediates. Chemical shifts of the transient species are not much different from $\mathrm{Nb}_{9} \mathrm{P}_{5}$, which suggests to us that the structures of the transient species can be similar to $\mathrm{Nb}_{9} \mathrm{P}_{5}$, but perhaps decorated differently with peroxo groups that affect the ${ }^{31} \mathrm{P}$ chemical shifts. This observation is consistent with the ESI-MS results that the transient ${ }^{31} \mathrm{P}$ NMR peaks show partial dissociation and rearrangement of the molecule, but not wholesale destruction. The sharp transient peak at $-1 \mathrm{ppm}$ is tentatively assigned to $\left[\mathrm{H}_{3} \mathrm{Nb}_{5} \mathrm{PO}_{13}\left(\mathrm{O}_{2}\right)_{5}\right]^{3-}$, which was suggested by ESI-MS.

We note that well resolved ${ }^{31} \mathrm{P}$ NMR peaks are observable only when a stoichiometric amount of $\mathrm{H}_{2} \mathrm{O}_{2}$ is added; only a few broad peaks are observed during the reaction when more $\mathrm{H}_{2} \mathrm{O}_{2}$

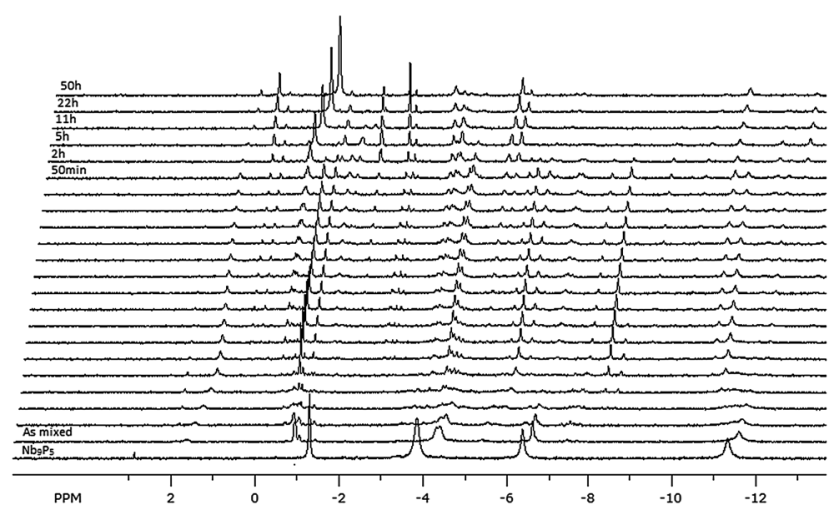

Fig. 4 Change of ${ }^{31} \mathrm{P}$ NMR spectra of $\mathrm{Nb}_{9} \mathrm{P}_{5}(30 \mathrm{mM})$ as a function of time after the addition of one equivalent of $\mathrm{H}_{2} \mathrm{O}_{2}$. The spectra are slightly offset to $x$-axis to show the peak changes more clearly. The spectra were taken every 3 minutes after addition of $\mathrm{H}_{2} \mathrm{O}_{2}$ for 1 hour and the last spectrum was taken 50 hours later. is added, possibly due to fast speciation changes and disorder upon peroxidation. The reaction is complete after one day when slight excess $\mathrm{H}_{2} \mathrm{O}_{2}$ is added, but the reaction is faster when a larger excess of $\mathrm{H}_{2} \mathrm{O}_{2}$ is added. The growing peak of peroxo- $\mathrm{Nb}_{4} \mathrm{P}_{2}$ shifts upfield to $-1 \mathrm{ppm}$ during the reaction, which might be due to an increasing concentration of peroxo- $\mathrm{Nb}_{4} \mathrm{P}_{2}$. When the reaction is complete, only the peak of peroxo- $\mathrm{Nb}_{4} \mathrm{P}_{2}$ and a small phosphate peak near $1 \mathrm{ppm}$ are observed [Fig. 4].

The reverse reaction, converting peroxo- $-\mathrm{Nb}_{4} \mathrm{P}_{2}$ to $\mathrm{Nb}_{9} \mathrm{P}_{5}$, can be achieved by hydrothermal treatment of a solution of peroxo- $-\mathrm{Nb}_{4} \mathrm{P}_{2}$ at $120{ }^{\circ} \mathrm{C}$ overnight. It is not surprising that heat destroys the peroxide moieties, but the $\mathrm{Nb}_{9} \mathrm{P}_{5}$ forms readily because both clusters have a similar $\mathrm{Nb}: \mathrm{P}$ ratio and because $\mathrm{Nb}_{9} \mathrm{P}_{5}$ is stable at near-neutral conditions ( $\left.\mathrm{pH} \sim 7\right)$. The sensitivity of the peroxide moieties to heat suggests a strategy for laser-patterning of films.

In summary, a new niobium-phosphate cluster is described that is stable over a wide range of solution $\mathrm{pH}$. This cluster thus adds to the small library of polyoxoniobate compounds that can be processed in acidic solutions. Most interestingly, the cluster can reversibly interconvert to and from the peroxo- $\mathrm{Nb}_{4} \mathrm{P}_{2}$, which suggests an easy means of patterning. This new cluster may be viewed as a molecular form of the solid niobium-phosphate catalyst that is so useful in industrial applications.

This work was supported by an NSF CCI grant through the Center for Sustainable Materials Chemistry, number CHE-1102637. Additional support to JHS was via NSF-CHE-1307556 to WHC. We thank Dr Ping Yu for acquisition of ${ }^{31} \mathrm{P}$ MAS NMR spectra. We also thank Zamirbek Akimbekov and Prof. Alexandra Navrotsky for TGA data and Jiarui Wang for XRD.

\section{Notes and references}

1 (a) T. Armaroli, G. Busca, C. Carlini, M. Giuttari, A. M. R. Galletti and G. Sbrana, J. Mol. Catal. A: Chem., 2000, 151, 233-243; (b) P. Carniti, A. Gervasini, S. Biella and A. Auroux, Catal. Today, 2006, 118, 373-378; (c) Y. Zhang, J. J. Wang, J. Ren, X. H. Liu, X. C. Li, Y. J. Xia, G. Z. Lu and Y. Q. Wang, Catal. Sci. Technol., 2012, 2, 2485-2491; (d) R. M. West, M. H. Tucker, D. J. Braden and J. A. Dumesic, Catal. Commun., 2009, 10(13), 1743-1746; (e) A. Florentino, P. Cartraud, P. Magnoux and M. Guisnet, Appl. Catal., A, 1992, 89, 143-153; $(f)$ T. Okuhara, Chem. Rev., 2002, 102, 3641-3666; (g) V. V. Ordomsky, V. L. Sushkevich, J. C. Schouten, J. van der Schaaf and T. A. Nijhuis, J. Catal., 2013, 300, 37-46; (h) K. Nakajima, Y. Baba, R. Noma, M. Kitano, J. N. Kondo, S. Hayashi and M. Hara, J. Am. Chem. Soc., 2011, 133(12), 4224-4227.

2 (a) J. M. Longo and P. Kierkegaard, Acta Chem. Scand., 1966, 20, 72; (b) K. Beneke and G. Lagaly, Inorg. Chem., 1983, 22, 1503-1507.

3 (a) S. Okazaki and A. Kurosaki, Catal. Today, 1990, 8, 113-122; (b) S. Okazaki and N. Wada, Catal. Today, 1993, 16, 349-359; (c) P. Carniti, A. Gervasini, S. Biella and A. Auroux, Chem. Mater., 2005, 17, 6128-6136; (d) Y. Zhang, J. J. Wang, X. C. Li, X. H. Liu, Y. J. Xia, B. C. Hu, G. Z. Lu and Y. Q. Wang, Fuel, 2015, 139, 301-307.

4 (a) M. Nyman, F. Bonhomme, T. M. Alam, M. A. Rodriguez, B. R. Cherry, J. L. Krumhansl, T. M. Nenoff and A. M. Sattler, Science, 2002, 297, 996-998; (b) M. Nyman, F. Bonhomme, T. M. Alam, J. B. Pairse and G. M. B. Vaughan, Angew. Chem., Int. Ed., 2004, 43, 2787-2792; (c) F. Bonhomme, J. P. Larentzos, T. M. Alam, E. J. Maginn and M. Nyman, Inorg. Chem., 2005, 44, 1774-1785; (d) M. Nyman, C. R. Powers, F. Bonhomme, T. M. Alam, E. J. Maginn and D. T. Hobbs, Chem. Mater., 2008, 20, 2513-2521; (e) J.-H. Son, C. A. Ohlin, R. L. Johnson, P. Yu and W. H. Casey, Chem. - Eur. J., 2013, 19, 5191-5197; $(f)$ J.-H. Son, C. A. Ohlin, E. C. Larson, P. Yu and W. H. Casey, Eur. J. Inorg. Chem., 2013, 1748-1753; $(g)$ P. Huang, E.-L. Zhou, X.-L. Wang, C.-Y. Sun, H.-N. Wang, Y. Xing, K.-Z. Shao and 
Z.-M. Su, CrystEngComm, 2014, 16, 9582-9585; (h) J.-Q. Shen, Q. Wu, Y. Zhang, Z.-M. Zhang, Y.-G. Li, Y. Lu and E.-B. Wang, Chem. - Eur. J., 2014, 20, 2840-2848; (i) J.-Q. Shen, Y. Zhang, Z.-M. Zhang, Y.-G. Li, Y.-Q. Gao and E.-B. Wang, Chem. Commun., 2014, 50, 6017-6019.

5 M. Nyman, A. J. Celestian, J. B. Parise, G. P. Holland and T. M. Alam, Inorg. Chem., 2006, 45, 1043-1052.

6 J.-H. Son, D.-H. Park, D. A. Keszler and W. H. Casey, Chem. - Eur. J., 2015, 21, 6727-6731.

7 J.-H. Son and W. H. Casey, Chem. Commun., 2015, 51, 1436-1438.

8 (a) D. Atencio, J. M. V. Coutinho, A. C. Doriguetto, Y. P. Mascarenhas, J. Ellena and V. C. Ferrari, Am. Mineral., 2008, 93, 81-87; (b) R. Tsunashima, D.-L. Long, H. N. Miras, D. Gabb, C. P. Pradeep and L. Cronin, Angew. Chem., Int. Ed., 2010, 49, 113-116.

9 M. I. Khan, Q. Chen, J. Zubieta, D. Goshorn and R. C. Haushalter, Inorg. Chim. Acta, 1992, 191, 97-102.

10 (a) J.-H. Son, J. Wang, F. E. Osterloh, P. Yu and W. H. Casey, Chem. Commun., 2014, 50, 836-838; (b) J.-H. Son, J. Wang and W. H. Casey, Dalton Trans., 2014, 43, 17928-17933; (c) J.-H. Son, C. A. Ohlin and W. H. Casey, Dalton Trans., 2013, 42, 7529-7533; (d) C. A. Ohlin, E. M. Villa, J. C. Fettinger and W. H. Casey, Angew. Chem., Int. Ed., 2008, 47, 5634-5636.

11 J.-H. Son and W. H. Casey, Dalton Trans., 2013, 42, 13339-13342. 